\title{
Enzyme-Linked Immunosorbent Assay Unit per Milliliter
}

National Cancer Institute

\section{Source}

National Cancer Institute. Enzyme-Linked Immunosorbent Assay Unit per Milliliter. NCI

Thesaurus. Code C68877.

A unit for measuring potency of immunologically active substance in a product

determined as reactivity in a quantitative immunoassay for particular antigen or antibody and expressed per unit volume equal to one milliliter. 